\title{
Study on Effect of Climate Warming to Carbon Cycle of Terrestrial Ecosystem Based on Fuzzy Evaluation
}

\author{
Lu Gan
}

Nanchang Institute of Science \&Technology, Nanchang 330108,China

\begin{abstract}
Keywords: Climate warming; terrestrial ecosystem; carbon cycle; model
\end{abstract}
\begin{abstract}
As one of the main manifestations of global change, climate warming effect on global terrestrial carbon cycles, this effect has important guiding significance for the development of accurate understanding of the carbon cycle process and related policies, through a lot of research work, this paper based on the fuzzy evaluation method to illustrate the ecological impact of climate warming on land, in the next few years or even decades, the synergistic effect of other manifestations of climate warming and global change will be the next focus of the study, climate change and terrestrial ecosystem between the two-way feedback mechanism is the theoretical basis for more accurate study, the structure and function of ecosystem climate change is the premise to accurately understand and predict future climate scenarios.

As one of the main manifestations of global change, climate warming has become an indisputable fact. It is current global average temperature is higher than the average temperature over the past few thousand years. At present, there is strong evidence that human activities lead to the continuous accumulation of greenhouse gases in the atmosphere, so that the gradual rise in global temperatures. According to the forecast, the $\mathrm{CO} 2$ effect of carbon dioxide and other greenhouse gases will cause the global average temperature to rise $0.2^{\circ} \mathrm{C}$ every 10 years. According to the prediction, the global temperature will be a huge change hitherto unknown in the past 10000 years, resulting in the potential impact on the global environment such as climate warming, it can cause a series of environmental problems, such as flat and rising, precipitation distribution pattern change, and the direct and indirect impact on terrestrial ecosystems.

The carbon cycle of terrestrial ecosystem is the research focus of global change, which is closely related to global climate change. Climate warming will lead to changes in the global carbon cycle of terrestrial ecosystems, the original carbon balance has been destroyed, and causes a series of environmental problems, such as rising sea level, precipitation pattern changes, etc.. It should be said that the impact of climate warming on terrestrial ecosystems is the core issue in the study of global change.

Climate warming has an impact on vegetation carbon pool and soil carbon pool by affecting NPP, it can change the yield and decomposition rate of litter.
\end{abstract}

\section{Effect of vegetation on carbon pool of terrestrial ecosystem}

The vegetation carbon pool is generally referred to as the part of the plant, which includes the aboveground parts of the plant and the living roots underground. As a producer of the ecosystem, the plant is required to maintain a constant amount of carbon dioxide per day to maintain the normal functioning of the ecosystem. The global vegetation stored carbon pool is about 550 to $950 \mathrm{PgC}$, with almost atmospheric carbon pool, but its activity is very high, which is the main process of the carbon cycle and carbon exchange between the atmospheres, thus affecting its change of 
atmospheric carbon pool is very important. In the future under the condition of climate warming, terrestrial ecosystem vegetation carbon pool increase can reduce the atmospheric concentration of carbon dioxide and carbon pool increase rate, slow down the greenhouse effect; on the contrary, if the carbon reduction of vegetation, to increasing atmospheric carbon dioxide levels provide more carbon, forming a positive feedback, resulting in accelerated increase in atmospheric temperature. A lot of researches have been done on this problem, and the results are different.

Direct evidence can be obtained from the soil warming experiment, some scholars have found that after 5 years of soil warming forest units and the growth of tree stems increased by nearly $50 \%$. By using fuzzy evaluation method more evidence of climate warming, the Amazon basin vegetation carbon pool increased $2 \%$, with future climate scenarios of carbon response of vegetation to climate change with the scholars, the results showed that climate warming will cause global vegetation carbon storage increased by $12 \%$ to $16 \%$, despite the different climate scenarios caused by vegetation carbon pool change is different.

Research shows that from the past, climate warming will have a huge impact on the terrestrial vegetation carbon pool, and had a completely different effect on different ecological systems, the basic performance of vegetation carbon pool increased with the increase of latitude, tiny vegetation carbon loss existing in the low latitude region, more reasonable in the global scale the explanation is that there is a certain degree of trace increase.

\section{Effect on litter}

Terrestrial ecosystem litter refers to terrestrial ecosystems, biological (plant, animal and soil microbial composition) residue components, also known as litter, and is a combination of organic material with material and energy source for the decomposition of the litter, including aboveground litter and roots. Litter usually in months or years to form small vegetation per unit time, the unit time per unit area on the ground, the formation of litter. Litter fall dead, including wood, grass, litter and dead underground biomass is an important part of terrestrial ecosystem carbon pool, plays an irreplaceable role in maintaining the structure and function of ecosystem. Litter is an important reservoir of organic matter and nutrients, which is an important part of nutrient cycling in terrestrial ecosystems. Therefore, litter is a separate carbon pool and a major process in the carbon cycle, as it is one of the main pathways to maintain the aboveground carbon pool and the upper soil carbon pool.

The effect of climate warming on litter decomposition, on the one hand, is affected by the amount and quality of litter, On the other hand, climate warming also affects the decomposition rate of litter. The influence of climate warming on vegetation carbon pool is generally believed that climate warming can increase the vegetation carbon pool, and the plant is formed by a certain proportion of litter. So climate warming can increase the amount of litter. Some scholars believe that litter accumulation reflects the dynamic balance between litter production and litter loss, while global warming can increase the yield of forest litter. In general, the litter of forest ecosystem has a certain distribution pattern in the whole world. With the increase of latitude, the litter production decreased, while the litter accumulation increased.

At the same time, climate warming will affect the decomposition rate of litter. Because the litter decomposition is usually combined with physical, chemical and biological process, the temperature of the reaction process had different promoting effects, so climate warming with the decomposition temperature and precipitation changes can accelerate litter. Some scholars have found that temperature is one of the main factors controlling litter decomposition, and the increase of atmospheric temperature can significantly increase the decomposition rate of litter, and this effect is 
consistent in all ecosystems. Some people believe that climate warming generally accelerates the decomposition of litter, but the apparent $\mathrm{Q}_{10}$ used to indicate this effect decreases with increasing temperature. At the same time, it is also believed that the increase of temperature and carbon dioxide can lead to the increase of carbon storage in plants, which leads to the increase of $\mathrm{C} / \mathrm{N}$ ratio and the decomposition rate of litter. In short, the impact of rising temperatures is mainly reflected in the increase of litter decomposition rate, and indirect effects of climate warming on litter decomposition on soil nutrient quality, reflected in the litter availability and the effects of freezing depth, thereby affecting the litter decomposition rate.

\section{Effect on soil carbon pool of terrestrial ecosystem}

Soil carbon pool includes organic carbon and inorganic carbon in the soil, as well as dead roots and biological secretions. Because the inorganic carbon in the carbonate form, very low activity, not sensitive to environmental factors, so in the previous studies on soil organic carbon mainly refers to the soil organic carbon pool to adopt the old habits, this paper refers to the soil carbon pool includes only the soil organic carbon pool. Under the condition of global temperature change, the soil of terrestrial ecosystem must be carbon or carbon sink, that is to say, climate warming will change the carbon exchange between soil and atmosphere. According to previous studies, mainly the impact of climate warming on soil carbon pool in terrestrial ecosystem for three kinds of effects: increased soil organic matter decomposition, increase soil respiration and increase soil carbon input NPP, generally it can be thought of as a carbon pool increased and two carbon reduction process. Climate warming changes the size of the carbon pool by influencing the above processes.

In fact, the response of different ecosystems to climate change is different. It is generally believed that the content of organic carbon in tropical soil is relatively low, and the effect of soil carbon release is not strong under the condition of climate warming. The role of carbon sink into the soil is relatively strong, so climate warming will eventually lead to an increase in soil carbon pool. While in the high latitude regions, climate warming will lead to a loss of soil carbon, and greatly exceed because of climate. The amount of carbon that is caused by warming makes the soil carbon. Among them, climate warming has the greatest influence on the soil carbon pool in high latitudes. To study the changes in the northern hemisphere tundra ecosystem carbon dynamics in a warming climate condition using the model, results show that the soil organic carbon pool will be reduced by $0.3 \%$, because the tundra carbon stock in large quantities, the carbon emissions will continue for a long time. At the same time for other ecosystem, climate warming may lead to increased soil carbon pool, the above results also show that the latitude zonal characteristics of carbon sink change, namely in warming conditions, high latitude regions generally showed reduced soil carbon, and soil carbon pool in low latitude regions may be constant or slightly increased.

\section{Study on the relationship between carbon source and sink of terrestrial ecosystem under climate warming}

The terrestrial ecosystem mainly through photosynthesis, autotrophic respiration and heterotrophic respiration and the exchange of carbon in the atmosphere, in the carbon balance state showed no net carbon emissions that are equal to carbon emissions. Climate warming can increase or decrease the rate or response of each process, and then affect the global terrestrial ecosystem

Carbon budget, as carbon or carbon sink. Scientists generally believe that climate warming can increase NPP emissions, and to accelerate the decomposition of soil organic matter, but what exactly is a dominant role, so far as the ratio of the different research results, and have different 
opinions.

The response mechanism of terrestrial ecosystems to climate warming is that climate warming can affect photosynthesis (usually increase), and high temperature will increase the potential and plant respiration, evaporation enhancement can cause the plant water stress, which leads to the decrease of NPP. On the other hand, the increase of temperature and the occurrence of water stress can lead to the increase of soil available $\mathrm{N}$, release the $\mathrm{N}$ restriction of plant, increase $N P P$.

\section{Conclusion}

At present, a large number of studies have been carried out on the impact of climate warming on terrestrial ecosystems, some problems have been reached consensus, but some problems still exist some differences and the improvement of research methods is the main directions in the future. At present, some preliminary conclusions have been drawn in this field.

\section{References}

[1] Goto N, Sakoda A, Suzuki M. Predicting the Effects of Global Warming on Terrestrial Ecosystems by Carbon Cycle Model.[J]. Kagaku Kogaku Ronbunshu, 1993, 19(5):771-780.

[2] Chen H, Li D, Gurmesa G A, et al. Effects of nitrogen deposition on carbon cycle in terrestrial ecosystems of China: A meta-analysis[J]. Environmental Pollution, 2015, 206:352..

[3] Xu X, Tian H, Wan S. Climate warming impacts on carbon cycling in terrestrial ecosystem[J]. Journal of Plant Ecology, 2007, 31(2):175-188.

[4] Xiao-Feng X U, Tian H Q. CLIMATE WARMING IMPACTS ON CARBON CYCLING IN TERRESTRIAL ECOSYSTEMS[J]. Journal of Plant Ecology, 2007, 31(2):175-188.

[5] Zeng N, Qian H, Roedenbeck C, et al. Impact of 1998-2002 midlatitude drought and warming on terrestrial ecosystem and the global carbon cycle[J]. Geophysical Research Letters, 2005, 32(22):45-81.

[6] Beier C, Schmidt I K, Kristensen H L. Effects of Climate and Ecosystem Disturbances on Biogeochemical Cycling in a Semi-Natural Terrestrial Ecosystem[J]. Water, Air, \& Soil Pollution: Focus, 2004, 4(2):191-206.

[7] Yi Y, Kimball J S, Jones L A, et al. Recent climate and fire disturbance impacts on boreal and arctic ecosystem productivity estimated using a satellite - based terrestrial carbon flux model[J]. Journal of Geophysical Research Biogeosciences, 2013, 118(2):606-622.

[8] Yi Y, Kimball J S, Jones L A, et al. Simulating the effects of fire disturbance and vegetation recovery on boreal ecosystem carbon fluxes[J]. American Geophysical Union, 2011.

[9] Kang S, Kimball J S, Running S W. Simulating effects of fire disturbance and climate change on boreal forest productivity and evapotranspiration.[J]. Science of the Total Environment, 2006, 362(1-3):85-102. 